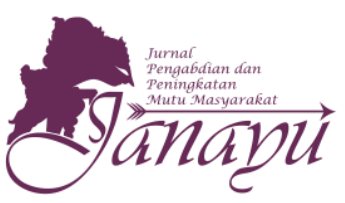

Website:

ejournal.umm.ac.id/index.php/janayu

*Correspondence:

tony.santiko@pip-semarang.ac.id

DOI: 10.22219/janayu.v2i2.16488

Sitasi:

Santiko, T., \& Tarzani, A,A. (2021).

Diklat Basic Safety Training (BST)

Kapal Layar Motor Sungai Liat

Kepulauan Bangka. Jurnal Pengabdian

dan Peningkatan Mutu Masyarakat,

2(2), 141-146.

Proses Artikel

Diajukan:

6 Mei 2021

Direviu:

3 Juni 2021

Direvisi:

3 Juli 2021

Diterima:

4 Juli 2021

Diterbitkan:

8 Juli 2021

Alamat Kantor:

Jurusan Akuntansi Universitas

Muhammadiyah Malang

Gedung Kuliah Bersama 2

Lantai 3.

Jalan Raya Tlogomas 246,

Malang, Jawa Timur,

Indonesia

P-ISSN: 2721-0421

E-ISSN: 2721-0340
Tipe Artikel: Paper Pengabdian

\section{Diklat Basic Safety Training (BST) Kapal Layar Motor Sungai Liat Kepulauan Bangka}

\author{
Tony Santiko ${ }^{1 *}$, Afdolludin Afta Tazani ${ }^{2}$ \\ Afiliasi: \\ 1,2Politeknik Ilmu Pelayaran Semarang, Semarang, Jawa \\ Tengah, Indonesia
}

\section{ABSTRACT}

The Government of the Republic of Indonesia through the Ministry of Transportation commissioned the Semarang Polytechnic of Shipping Science to conduct basic safety training (BST) of motor yachts to certify the crew of tourist boats and fishermen in Sungai Liat Bangka Regency. This activity is based on a letter of request from KSOP Sungai Liat to the Semarang Polytechnic of Shipping Sciences which aims to improve the competence of the Crew related to shipping safety and marine environmental pollution. Instructors and Lecturers of Semarang Polytechnic of Shipping Sciences as Resource Persons conduct education, training and counseling to the crew of tourist boats and Fishermen of Sungai Liat in order to implement safety and security in carrying out their duties and also support the protection of the marine environment for the common.

KEYWORDS: Ship's Crew; Basic Safety Trainin; Motorcycle Sailing Boat.

\section{ABSTRAK}

Pemerintah Republik Indonesia melalui Kementerian Perhubungan menugaskan Politeknik Ilmu Pelayaran Semarang untuk melakukan diklat laut Basic Safety Training (BST) Kapal Layar Motor guna menyertifikasi awak kapal wisata dan nelayan di Sungai Liat Kabupaten Bangka. Kegiatan ini berdasarkan Surat permintaan dari KSOP Sungai Liat kepada Politeknik Ilmu Pelayaran Semarang yang bertujuan untuk meningkatkan kompetensi Awak Kapal terkait keselamatan pelayaran dan pencemaran lingkungan laut. Instruktur dan Dosen Politeknik Ilmu Pelayaran Semarang sebagai Narasumber melakukan pendidikan, pelatihan dan penyuluhan terhadap Awak kapal wisata dan Nelayan Sungai Liat agar dapat menerapkan keselamatan dan keamanan dalam menjalankan tugasnya dan juga ikut mendukung menjaga lingkungan laut untuk kepentingan bersama.

KATA KUNCI: Awak Kapal; Basic Safety Training; Kapal Layar Motor. 


\section{PENDAHULUAN}

Kepulauan Bangka Belitung merupakan gugusan dua pulau yaitu Pulau Bangka dan Pulau

Belitung yang sekitarnya dikelilingi pulau-pulau kecil. Pulau-pulau yang mengitari Pulau Bangka antara lain Nangka, Penyu, Burung, Lepar, Pongok, Gelasa, Panjang, dan Tujuh. Sementara Pulau Belitung dikelilingi pulau-pulau kecil, antara lain Lima, Lengkuas, Selindung, Pelanduk, Seliu, Nadu, Mendanau, Batu Dinding, Sumedang dan pulau-pulau kecil lainnya. (Soraya B Larasati, 2019:24). Di kepulauan Bangka Belitung terdapat beberapa sungai, salah satunya adalah Sungai Liat. Sungai Liat yang berada di Kabupaten Bangka Kepulauan Bangka Belitung adalah sebuah daerah dengan wilayah kepulauan yang mempunyai potensi besar terhadap sumber daya alamnya berupa wisata bahari, transportasi laut dan perikanan. Sesuai dengan Keputusan Menteri Perhubungan Republik Indonesia KP 432 Tahun 2017, Kepulauan Bangka Belitung termasuk dalam Alur Laut Kepulauan Indonesia (ALKI). Dengan kondisi seperti ini Sungai Liat memiliki potensi besar dalam mewujudkan dan mendukung Indonesia sebagai Poros Maritim Dunia. Dalam mendukung hal ini harus diimbangi dengan Sumber Daya Manusia (SDM) yang memadai dan berkompeten dalam bidang kelautan dan pelayaran. Tingginya lalu lintas pelayaran baik kapal niaga, nelayan maupun kapal wisata serta kegiatan transportasi kepulauan yang mengandalkan transportasi melalui laut mewajibkan setiap awak kapalnya memiliki pengetahuan dasar mengenai keselamatan dan keamanan dalam berlayar dan pengetaghuan tentang pencemaran laut serta sertifikat awak kapal dalam rangka memenuhui peraturan dari Pemerintah.

KSOP Sungai Liat dalam memenuhi target sertifikasi awak kapalnya dan dalam rangka meningkatkan kompetensi pengetahuan awak kapalnya bekerja sama dengan Politeknik Ilmu Pelayaran Semarang sebagai Unit Pelaksana Teknis Diklat Kementerian Perhubungan sesuai dengan Keputusan Ditjen Perhubungan Laut Nomor PK.303/1/01/DK-17 tanggal 3 Januari 2017 tentang sertifikat approval Basic Safety Training. Politeknik Ilmu Pelayaran Semarang melaksanakan Diklat Basic Safety Training (BST) Kapal Layar Motor kepada awak kapal wisata dan nelayan di Sungai Liat untuk memberikan Pendidikan, pelatihan dan penyuluhan serta sertifikasi secara gratis tanpa dipungut biaya sedikitpun. "Basic Safety Training (BST), yaitu program diklat yang mengajarkan kepada peserta diklat agar mampu memiliki pemahaman tentang dasar-dasar keselamatan diatas kapal serta mampu mempraktekkan cara-cara mencegah dan mengatasi keadaan darurat" (Darul Prayogo, 2020:237). Diharapkan juga agar para peserta diklat dapat memenuhi persyaratan dalam Undang-Undang No.1 Tahun 1970 tentang Syarat-syarat Keselamatan Kerja. Hal ini sekaligus menjadi kewajiban bagi Politeknik Ilmu Pelayaran Semarang untuk melaksanakan salah satu TriDharma Perguruan Tinggi yaitu Pengabdian Masyarakat sesuai Peraturan Pemerintah Indonesia nomor 37 Tahun 2009 pasal 12 ayat 5.

Politeknik Ilmu Pelayaran Semarang Menugaskan Tim Diklatnya yang terdiri dari Tim BST KLM yang dipimpin oleh Tony Santiko, S.ST., M.Si., M.Mar.E dan Tim Instruktur yang dipimpin oleh Afdolludin Afta Tazani, S.Tr.Pel. Pelaksanaan diikuti oleh 240 orang yang terdiri dari awak kapal wisata dan nelayan Kabupaten Sungai Liat. Selain gratis peserta juga mendapat beberapa fasilitas seperti kamar hotel, konsumsi, sertifkat, alat keselamatan dan alat tulis serta perlengkapan Seragam Diklat. Sebelum bisa mengikuti diklat gratis ini, peserta harus mengumpulkan syarat berupa KTP, Ijasah minimal SD, dan lolos tes Kesehatan dari Tim Kesehatan Politeknik Ilmu Pelayaran Semarang.

\section{Janayu} 2.2 


\section{METODE}

Kegiatan ini dilaksanakan di Hotel Parai, Sungai Liat Kabupaten Bangka pada tanggal 21-23 Oktober 2019 dengan berbagai fasilitas yang mendukung seperti kolam renang besar, lahan yang luas, penginapan untuk peserta, aula indoor dan lapangan outdoor, tempat ibadah, restoran, parkir, serta terletak di tepi pantai yang sangat mendukung untuk kegiatan pelatihan. Kegiatan ini diikuti oleh warga sekitar yang berprofesi sebagai awak kapal wisata dan nelayan yang belom memiliki sertifikat Basic Safety Traing (BST) Kapal Layar Motor untuk menunjang pekerjaan sehari-hari.

Kegiatan ini di hadiri oleh Perwakilan dari KSOP Sungai liat, Perangkat Desa setempat, Perwakilan Kepolisian dan keamanan. Diklat ini dibuka oleh Kepala Bagian Umum dan Keuangan Politeknik Ilmu Pelayaran Semarang Bapak Slamet Riyadhi, M.Si mewakili Direktur Politeknik Ilmu Pelayaran Semarang dan dilanjutkan dengan regsitrasi peserta dan penyerahan syarat2 dari peserta ke panitia berupa KTP, Ijazah minimal SD, akta kelahiran dan surat keterangan tidak mampu dari Kelurahan, selanjutnya dilakukan pemeriksaan Kesehatan jasmani, buta warna dan pemeriksaan umum lain. Bagi peserta yang tidak lolos sesuai akan digantikan oleh peserta lainnya dan tidak dapat mengikuti diklat ini. Setelah dinyatakan lolos, peserta akan di foto untuk sertifikat. Kegiatan pembelajaran diklat ini di awali dengan pretest, materi teori selama satu hari, materi praktek selama 2 hari dan di akhiri dengan post test. Hasil dari praktek dan postest ini yang dijadikan tolak ukur keberhasilan peserta sehingga bisa dinyatakan lulus diklat atau tidak dengan skor minimal 70.

\section{HASIL DAN PEMBAHASAN}

Tony Santiko, S.ST., M.Si., M. Mar. E dan Afdolludin Afta Tazani, S.Tr. Pel sebagai salah satu Pengajar dan Instruktur memberikan materi Pendidikan dan Pelatian kepada peserta berdasarkan PK. 12/BPSDMP-2017 sehingga memenuhi syarat-syarat untuk mendapatkan sertifikat Basic Safety Training (BST) Kapal Layar Motor. Materi tersebut di laksanakan selama 3 (tiga) hari berupa teori dan praktek.

\section{Kegiatan 1}

Janayu 2.2
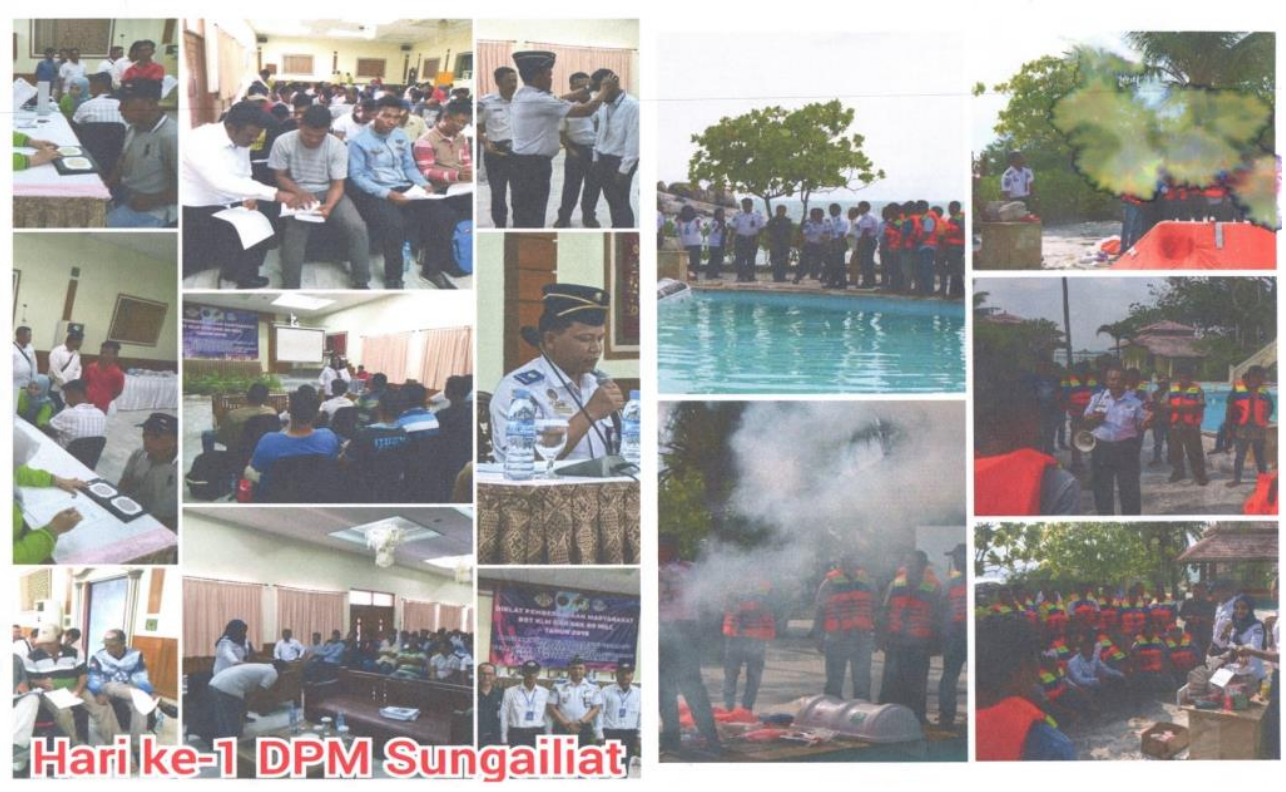

Gambar 1.

Personal Survival Technic (PST) 
Tony Santiko, S.ST., M.Si., M. Mar. E dan Afdolludin Afta Tazani, S.Tr. Pel sebagai salah satu Pengajar dan Instruktur memberikan materi Personal Survival Technic (PST) sesuai dengan STCW Code section A-VI/1 dengan kekhususan materi penyelamatan diri, situasi darurat, evakuasi, perlengkapan penyelamatan dan Radio darurat. Materi ini digunakan untuk melatih seseorang dalam Teknik penyelamatan diri dalam keadaan darurat dan penggunaan alat komunikasi darurat. Pada sesi kedua dilanjutkan dengan Materi dasar P3K yaitu pertolongan pertama pada korban kecelakaan berupa cara pernapasan buatan, penanganan syok, luka bakar, pendarahan dan cara mengangkat korban. Pelatihan ini dilakukan secara teori dan praktek langsung sehingga peserta mampu melakukan pertolongan pertama pada kecelakaan.

\section{Kegiatan 2}

Pada hari kedua dilanjutkan dengan materi teori Fire Prevention and Fire Fighting $(\mathrm{FP} / \mathrm{FF})$ yaitu pelatihan pada penanganan kebakaran, pencegahan kebakaran, jenis-jenis alat pemadam dan metode pemadaman kebakaran sesuai dengan aturan yang terdapat di dalam Safety Of Life at Sea (SOLAS) Chapter III Regulation9.3.4. Peserta dilatih untuk dapat mengenali jenis-jenis kebakaran dan cara pemdamannya secara cepat dan tepat. Sesi kedua dilanjutkan dengan materi teori Personal Safety Social Responsibility (PSSR) yaitu materi tentang tanggung jawab keamanan, keselamatan, perlindungan pencemaran lingkungan laut dan komunikasi sosialisasi antar manusia di atas kapal. Materi ini melatih bagaimana peserta dapat bertanggung jawab terhadap pekerjaanya dengan aman dan selamat dengan menjaga lingkungan laut dari pencemaran sesuai dengan yang tertuang di dalam PP No.19 Tahun 1999 tentang Pengendalian Pencemaran dan atau Perusakan laut. Ditambah peserta harus bisa membangun komunikasi vang harmonis antar awak kapal di atas kapal.

Gambar 2.

Teori Fire

Prevention and

Fire Fighting

(FP/FF))
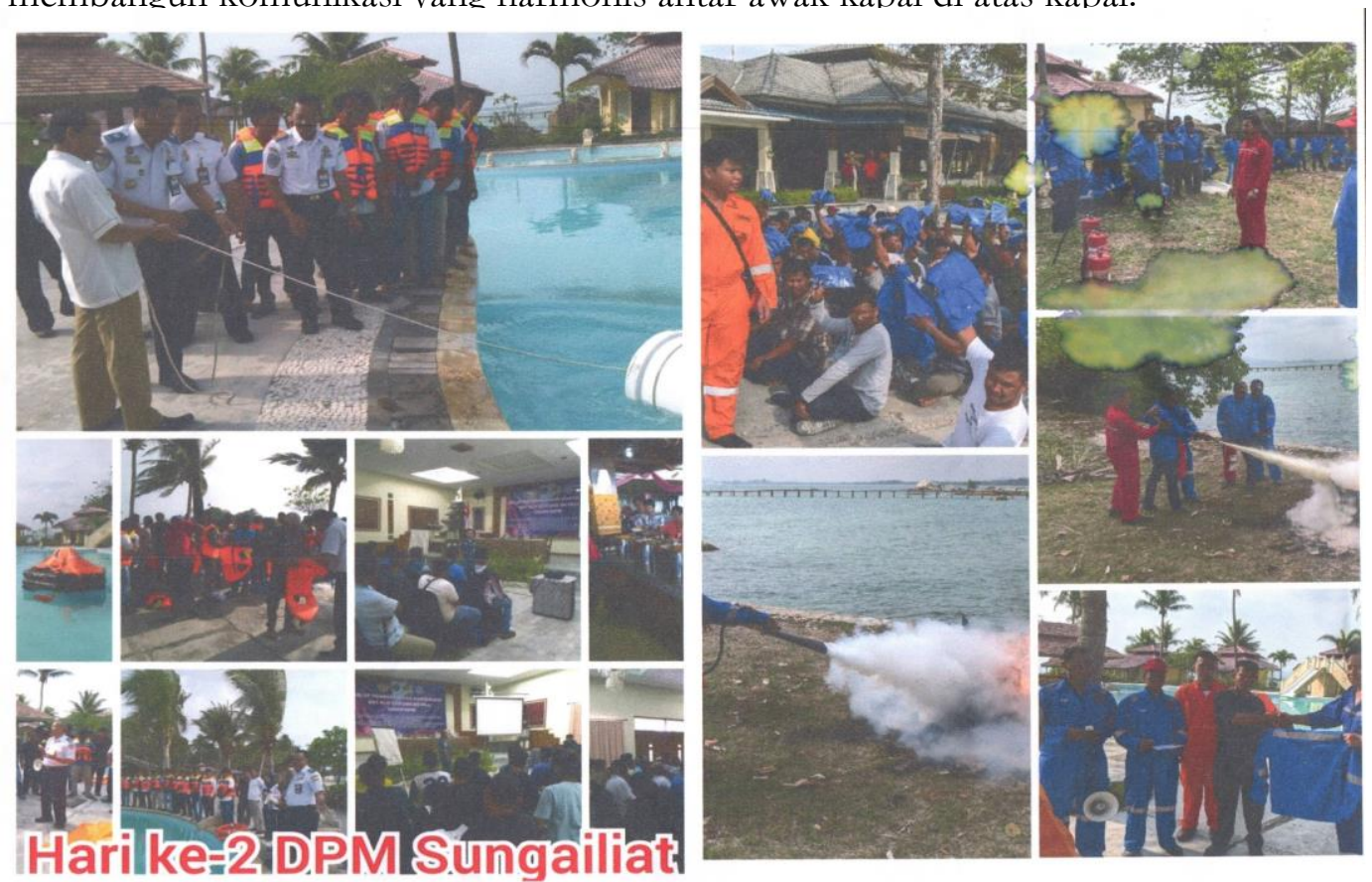


\section{Kegiatan 3}
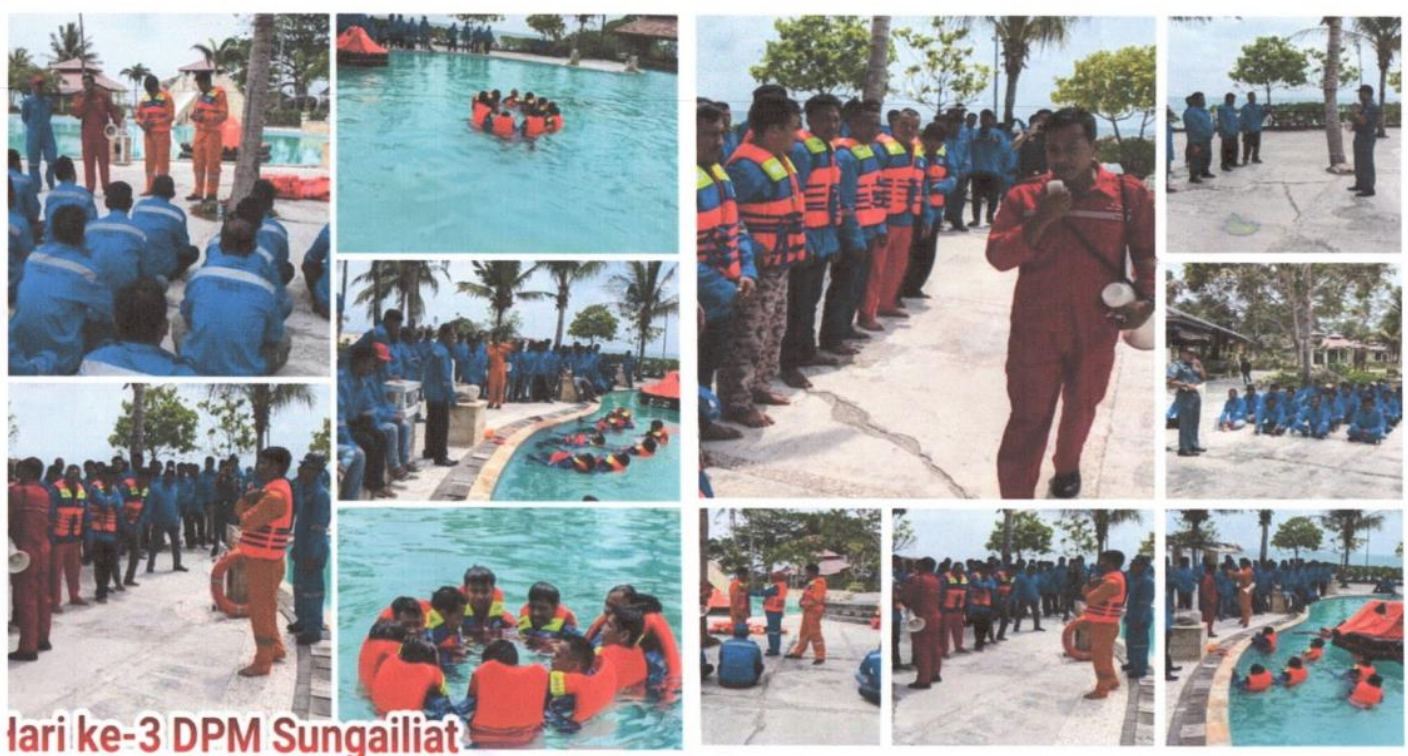

Gambar 3.

Praktek

Langsung Fire

Prevention and

Fire Fighting

$(\mathrm{FP} / \mathrm{FF})$

Hari ketiga pelatihan, materi dilanjutkan dengan materi praktek langsung Fire Prevention and Fire Fighting (FP/FF) yaitu praktek menggunakan alat pemadam kebakaran dan Latihan memadamkan kebakaran. Hal ini agar peserta menjadi terlatih dan tidak panik menghadapi kebakaran. Sesi kedua praktek dilanjutkan dengan materi praktek Personal Survival Technic (PST) yang dilakukan di kolam renang Hotel tempat menginap dengan Latihan cara-cara penyelamatan diri di air, perlengkapan keselamatan di atas kapal, dan peralatan darurat isyarat darurat di atas kapal.

\section{Hasil Kegiatan}

Kegiatan diklat berlangsung secara antusias oleh peserta terbukti dengan banyaknya perntanyaan dan sharing dari Pengajar maupun Instruktur dan Peserta atau sebaliknya. Pada akhir hari ketiga setelah semua diklat teori maupun praktek dilaksanakan, peserta melakukan post test dan peserta juga di uji untuk melakukan praktek langsung dari materi yang sudah diberikan guna melihat tingkat keberhasilan peserta selama mengikuti kegiatan. Nilai minimum untuk bisa lulus adalah 70. Terbukti dari seluruh peserta yang hadir sebanyak 240 orang semua dinyatakan lulus dan memenuhi persyaratan untuk mendapatkan sertifikat. Ini menandakan tercapainya tujuan diklat yaitu untuk membekali dan meningkatkan kompetensi pengetahuan awak kapal wisata dan nelayan tentang pengetahuan dasar Basic Safety Training (BST) Kapal Layar Motor. Sehingga ikut mendukung dalam upaya melakukan pelayaran yang aman dan selamat, menjaga lingkungan laut dari pencemaran dan ikut mendukung mengurangi kecelakaan di perairan.

\section{SIMPULAN}

Hasil kegiatan yang dilakukan masih belum merata kepada seluruh masyarakat yang berprofesi sebagai awak kapal wisata maupun nelayan di daerah pesisir terlebih yang belum

Janayu

2.2 memiliki sertifikat basic safety training (BST) Kapal Layar Motor.

Selanjutnya kegiatan seperti ini diharapkan dapat segera merata kepada seluruh masyarakat yang berprofesi sebagai awak kapal wisata dan nelayan sebagai penunjang dalam pekerjaan dalam memenuhi peraturan Pemerintah dan meningkatkan keselamatan dan keamanan dalam pelayaran serta pencegahan pencemaran lingkungan laut 


\section{DAFTAR PUSTAKA}

Keputusan Direktorat Jenderal Perhubungan Laut Nomor PK. 303/1/01/DK-17 Tanggal 3 Januari 2017 Tentang Sertifikat Approval Basic Safety Training., 2017)

Keputusan Menteri Perhubungan Republik Indonesia KP. 432 Tahun 2017 Tentang Kepulauan Bangka Belitung Termasuk Dalam Alur Laut Kepulauan Indonesia (ALKI), 2017)

Peraturan Kepala Badan Pengembangan Sumber Daya Manusia Perhubungan Nomor PK. 12/BPSDMP-2017 Tentang Kurikulum Basic Safety Training Kapal Layar Motor, 2017)Peraturan Pemerintah Indonesia Nomor 37 Tahun 2009 Pasal 12 Ayat 5 Tentang TriDharma Perguruan Tinggi, 2009)

Larasati, Soraya B. (2019). Profil Provinsi Kepulauan Bangka Belitung 2019 Potensi dan Pesona Bumi Serumpun Sebalai. Pangkalpinang:PT Micepro Indonesia.

Peraturan Pemerintah Nomor 19 Tahun 1999 tentang Pengendalian Pencemaran dan atau Perusakan Laut. 1999

Prayogo, Darul. (2020). Pelatihan Basic Safety Training (BST) kepada Nelayan Tegal untuk Menunjang Keselamatan Pelayaran. E-DIMAS:Jurnal Pengabdian kepada Masyarakat, 11 (2), 236-239.

Safety Of Life at Sea (SOLAS) 1974 Chaper III tentang Alat-alat Keselamatan dan Penempatannya. 1974

Standard Of Training, Certification and Watchkeeping fo Seaferers (STCW) 1978 Section A-VI/1 tentang Pelaut Harus Menerima Sosialisasi Keselamatan dan Pelatihan atau Instruksi Dasar. 1978

Undang-Undang Republik Indonesia Nomor 1 Tahun 1970 tentang Syarat-Syarat Keselamatan Kerja. 1970. Jakarta 